\title{
Studi Komparatif Kinerja Keuangan Daerah Induk dan Daerah Pemekaran (Kabupaten/Kota di Provinsi Jambi)
}

\author{
Endah Tri Kurniasih ${ }^{1}$, Etik Winarni ${ }^{2}$, Ahmad Soleh $^{3}$ \\ 1,2,3 Universitas Muhammadiyah Jambi \\ Corespondence Autor Email: mas.soleh@yahoo.com
}

\begin{abstract}
Based on Law No. 33/2004 on the transfer of power from the central government to the local government in managing, collecting and managing the source of receipt in accordance with the potential and conditions of their respective regions or seized by fiscal decentralization. In order to realize this goal, local governments are allowed to carry out regional expansion. The purpose of the expansion is to optimize services to the community in light of the growing population development. To improve service performance, it is certainly required to have sufficient financial capabilities. In order to ensure the implementation of the implementation, the financial capabilities of each region are required, but regional autonomy often creates fiscal gaps and becomes a burden on the central government as a result of the inability to finance development carried out by local governments. Therefore, efforts are needed to improve and find alternative sources of new admissions taking into account the conditions and potential that exist in each area. On the basis of the problem, this research needs to be carried out to see if the implementation of regional autonomy has been effectively carried out in accordance with the objective of regional autonomy which is to achieve fiscal independence. The objectives of this study are (1) analyzing the financial capabilities of the expansion area and the parent region (2) analyzing how the new and parent districts receive efforts in the implementation of fiscal maturity. The data used in this study is secondary data of danalm bentum time series in the period 2009-2017 sourced from Dispenda, BPS and related agencies from 11 districts / cities in Jambi Province. Analysis of data used by nature of this study with models of fiscal decentralization degrees (FDD), Regional Spending Performance and Regional Financial Retdor. While to measure tax efforts used the Tax Ratio and Tax Capacity model.
\end{abstract}

Keywords: Comparison Study, Regional Financial Performance

\section{Pendahuluan}

Berdasarkan undang-undang No. 32 Tahun 2004 tentang pemerintah daerah, pemerintah pusat telah memberikan kekuasan bagi pemerintahn daerah dalam mengelola keuangan daerahnya sendiri dengan cara memungut serta menggunakan sendiri sumber-sumber penerimaan sesuai dengan potensi dan kondisi daerahnya masing-masing. Pemekaran ini berguna agar daerah dapat mengoptimalkan pendapatan daerahnya, dari sisi kinerja dengan adanya pemekaran daerah tentunya mempermudah pemerintah dalam mengelola kinerja keuangan, hal ini disebabkan luas cangkupan daerah yang dikelola juga semakin mengecil. Pendapat Swianiewicz (2011) bahwa komunitas yang lebih kecil dan lebih homogen akan lebih mudah mengimplementasikan kebijakan yang sesuai dengan preferensi sebagian besar masyarakat.

Untuk menjamin tercapainya tujuan diselenggarakannya otonomi daerah, diperlukan kemampuan untuk meningkatkan kemampuan keuangan sendiri, yakni dengan upaya peningkatan PAD, baik dengan meningkatkan penerimaan sumber PAD yang sudah ada maupun dengan penggalian sumber PAD yang baru sesuai dengan ketentuan, kondisi dan potensi ekonomi masyarakat dari masing-masing daerahnya. Dalam meningkatkan penerimaan PAD pemerintah cenderung menggali potensi penerimaan pajak daerahnya hal ini disebabkan kontribusi terbesar terhadap penerimaan pemerintah berasal di sektor pajak daerah, oleh sebab itu jika penerimaan pajak baik mengindikasikan bahwa kinerja keuangan juga baik. Dengan pengelolaan keuangan yang baik dan pendapatan daerah yang tinggi akan diharapkan akan mengurangi beban pemerintah pusat sehingga tingkat ketergantungan daerah terhadap pemerintah pusat akan semakin berkurang, dengan demikian terciptalah kemandirian daerah. yang akhirnya tercapailah pelaksanaan otonomi daerah. Namun pada kenyataanya Pemekaran daerah eringkali menyebabkan kesenjangan fiskal antar daerah akibatnya terjadinya pembebanan keuangan pada pemerintah pusat, sebagai akibat ketidakmampuan pembiayaan pembangunan yang dilakukan oleh pemerintah daerah.

Hal ini sesuai dengan penelitian yang dilakukan Zuhro (2009) yang menyatakan dampak negatif dari pemekaran daerah di Indonesia adalah pemekaran menciptakan perluasan struktur yang mengakibatkan beban berat pembiayaan, rendahnya kapasitas fiskal yang menyebabkan pemerintah daerah berupaya meningkatkan pendapatan dengan berbagai cara yang justru merugikan masyarakat yang berakibat munculnya kesenjangan. Hal ini tentu saja tidak sesuai dengan tujuan otonomi daerah, yakni mewujudkan kemandirian daerah dengan potensi-potensi yang di miliki. Atas dasar permaslaahan tersebut maka penelitian ini bertujuan untuk menganalisis perbandingan kinerja keuangan, upaya pajak antara daerah induk dan daerah pemekaran. 


\section{Tinjauan Pustaka \\ Pemekaran Daerah}

Pemekaran daerah adalah pemecahan provinsi atau kabupaten/kota menjadi dua daerah atau lebih (PP No.78 Tahun 2007). Pemekaran daerah berarti pengembangan dari satu daerah otonom menjadi dua atau lebih daerah otonom. Pemekaran daerah dilandasi oleh Undang-undang nomor 34 tahun 2000 tentang Pemerintahan Daerah, pada pasal 5 ayat 2 dinyatakan daerah dapat dimekarkan menjadi lebih dari satu daerah, namun setelah UU No.22 tahun 1999 diganti dengan UU No.32 tahun 2004 tentang Pemerintahan daerah. Tujuan pemekaran sebagaimana tertuang dalam berbagai peraturan perundangan dimaksudkan untuk meningkatkan kesejahteraan masyarakat.

\section{Otonomi daerah}

Otonomi daerah diartikan sebagai wewenang/kekuasaan pada suatu wilayah/daerah yang mengatur dan mengelola untuk kepentingan wilayah masyarakat itu sendiri mulai dari ekonomi, politik dan pengaturan perimbangan keuangan. Menurut Undang-Undang No. 32/2004 tentang Pemerintahan Daerah Pasal 1 butir 5, otonomi daerah didefinisikan sebagai hak, wewenang, dan kewajiban daerah otonom untuk mengatur dan mengurus sendiri urusan pemerintahan dan kepentingan masyarakat setempat sesuai dengan peraturan perundang-undangan. Hubungan antara pusat dan daerah menurut Undang-Undang Nomor 34/2004 dinyatakan dalam tiga prinsip, yaitu desentralisasi, dekonsentrasi dan tugas pembantuan.

\section{Kinerja Keuangan Daerah}

Menurut Bastian (2006) kinerja adalah gambaran pencapaian pelaksanaan suatu kegiatan/program/kebijaksanaan dalam mewujudkan sasaran, tujuan, misi, dan visi organisasi. Sehingga kinerja keuangan pemerintah daerah adalah kemampuan suatu daerah untuk menggali dan mengelola sumber-sumber keuangan asli daerah dalam memenuhi kebutuhannya guna mendukung berjalannya sistem pemerintahan, pelayanan kepada masyarakat dan pembangunan daerahnya.

Susantih dan Saftiana (2009) menyatakan kinerja keuangan Pemerintah Daerah adalah kemampuan suatu daerah untuk menggali dan mengelola sumber-sumber keuangan asli daerah guna memenuhi kebutuhannya agar tidak tergantung sepenuhnya kepada Pemerintah Pusat. Sehingga mempunyai keleluasaan dalam menggunakan dana tersebut untuk kepentingan masyarakat daerah dalam batas-batas yang diatur berdasarkan peraturan perundangundangan.

\section{Metode Penelitian}

Metode yang digunakan dalam penelitian ini menggunakan analisis deskriptif kuantitatif dan kualitatif dengan menggunakan data sekunder dalam bentuk time series dalam kurun waktu 2009-2017, yang bersumber dari Dinas Pendapatan Daerah (Dispenda) dan Badan Pusat Statistik (BPS) dan instansi lainnya yang berkaitan dengan penelitian pada 11 kabupaten/kota di Provinsi Jambi.

\section{Alat Analisis Masalah Pertama}

Untuk menjawab permasalahan pertama yaitu mengukur perbandingan kinerja keuangan daerah dilakukan dengan model:

1. Derajat Otonomi Fiskal; digunakan formulasi derajat otonomi, sebagaimana dikemukakan oleh Mahmudi (2007): $D O F_{t}=\frac{P A D_{t}}{T P D_{t}} \times 100 \%$

Dimana: DOF $=$ Rasio Derajat Otonomi Fiskal tahun t; PAD = Nilai Total Pendapatan Asli Daerah tahun t; TPD $=$ Nilai Total Pendapatan Daerah tahun $\mathrm{t}$

Tabel 1.

Ukuran interval $\mathrm{DOF}$

\begin{tabular}{ll}
\hline Nilai Rasio $(\%)$ & Kriteria DOF \\
\hline $0-20$ & Rendah Sekali, Tidak otonom \\
$20,1-40$ & Rendah, Kurang otonom \\
$40,1-60$ & Cukup tinggi, Cukup otonom \\
$60,1-80$ & Tinggi, otonom \\
$80,1-100$ & Sangat tinggi, otonom daerah sangat tinggi \\
\hline
\end{tabular}

Sumber : Agustina, (2010) dalam (Tangkilisan, 2005)

2. Kinerja Belanja Daerah; digunakan formulasi, sebagai berikut. (Tangkilisan, 2005): $K B D=\frac{B L}{T B D} X 100 \%$ Dimana: KBD: Kinerja Belanja Daerah; BL : Belanja Langsung; TBD : Total Belanja Daerah 
Endah Tri Kurniasih et al, Studi Komparatif Kinerja Keuangan Daerah Induk dan Daerah Pemekaran (Kabupaten/Kota di Provinsi Jambi)

Dalam pengambilan keputusan untuk menilai kemampuan rutin daerah maka digunakan skala interval sebagai beikut (Agustina, 2010) dalam (Tangkilisan, 2005):

Tabel 2.

Ukuran interval Kriteria Kinerja Belanja

\begin{tabular}{ll}
\hline Nilai Rasio $(\%)$ & Kriteria Kinerja Belanja \\
\hline $0-20$ & Sangat Buruk \\
$20,1-40$ & Buruk \\
$40,1-60$ & Cukup \\
$60,1-80$ & Baik \\
$80,1-100$ & Sangat Baik, \\
\hline
\end{tabular}

Sumber : Agustina, (2010) dalam (Tangkilisan, 2005)

3. Derajat Ketergantungan Keuangan Daerah digunakan formulasi yang dikemukakan oleh Mahmudi (2007). $R K K D_{t}=\frac{D B P_{t}}{T P D_{t}} \times 100 \%$

Dimana: RKKDt $=$ Rasio Ketergantungan Keuangan Daerah tahun $t$; DBP $=$ Dana Bantuan Pusat tahun $t$; $\mathrm{TPD}=$ Total Pendapatan Daerah tahun $\mathrm{t}$

Pengambilan keputusan : semakin tinggi rasio ketergantungan keuangan anggaran pendapatan daerah maka semakin jelek pengelolaan keuangan daerah begitupun sebaliknya semakin tinggi pengelolaan keuangan daerah maka semakin mandiri suatu daerah. Nilai konversi adalah nilai rasio yang diperkecil sehingga nilai yang dikonversikan dapat diambil keputusan: jika nilai konversi semakin rendah maka tingkat ketergantungan keuangan semakin tinggi. begitupun sebaliknya jika semakin tinggi nilai konversi maka semakin rendah tingkat ketergantungan keuangan daerah. Ukuran interlval Rasio Ketergantungan Keuangan Daerah adalah sebagai berikut:

Tabel 3.

Ukuran Interval Kriteria RKKD

\begin{tabular}{clcl}
\hline Nilai Rasio (\%) & \multicolumn{1}{c}{ Kriteria KKD } & Nilai Rasio Conversi (\%) & Kriteria \\
\hline $0-20$ & Rendah sekali, Tidak tergantung & $0-20$ & Sangat Tinggi \\
$20,1-40$ & Rendah, Tergantung Rendah & $20,1-40$ & Tinggi \\
$40,1-60$ & Cukup tinggi, Cukup Tergantung & $40,1-60$ & Cukup Tinggi \\
$60,1-80$ & Tinggi, Tergantung Tinggi & $60,1-80$ & Rendah \\
$80,1-100$ & Sangat tinggi, sentralisasi & $80,1-100$ & Rendah Sekali \\
\hline
\end{tabular}

Sumber : Mahmudi (2007)

\section{Hasil}

Analisis Kinerja Keuangan Daerah Induk dan Daerah Pemekaran di Kabupaten/Kota di Provinsi Jambi.

Tabel 4

Pola Rata-rata Kinerja Keuangan Kabupaten/Kota Daerah induk dan daerah pemekaran di Provinsi Jambi Tahun 2009-2016

\begin{tabular}{lllrlrl}
\hline \multirow{2}{*}{ Rata-rata } & \multirow{2}{*}{ DOF } & \multicolumn{2}{c}{ RKKD } & \multirow{2}{*}{ Pola Hubungan } & \multirow{2}{*}{ KBD } \\
\cline { 2 - 4 } & & Rill & Conversi & & Instruktif & 50,892 \\
Induk & 6,196 & 81,968 & 18,032 & & Instruktif & 59,418 \\
Pemekaran & 4,246 & 85,048 & 14,952 & & \\
\hline
\end{tabular}

Sumber : Hasil Olahan Data

Tabel 4 dianalisis bahwa kinerja daerah induk lebih tinggi dibandingkan dengan daerah pemekaran. Meskipun rata-rata daerah mempunyai pola hubungan Instruktif yang artinya sudah Pemerintah Daerah masih sangat tergantung dengan pemerintah pusat. KBD daerah pemekaran lebih tinggi di bandingkan dengan daerah induk hal ini disebabkan Kinerja Belanja Daerah (KBD) Pemekaran lebih banyak di bandingkan dengan daerah induk. namun secara variabel DOF, dan RKKD lebih unggul daerah induk dibandingkan dengan daerah pemekaran.

\section{Simpulan}

Analisis Kinerja Keuangan Daerah Induk dan Daerah Pemekaran Kabupaten/Kota di Provinsi Jambi menunjukan bahwa dari sisi kinerja keuangan daerah, daerah induk lebih unggul dari pada daerah pemekaran meskipun kedua daerah tersebut tergolong tidak otonomi pelaksanaan otonomi daerah di kabupaten/kota di Provinsi Jambi tidak Efektif. 


\section{Daftar Pustaka}

Agustina, N. 2010. Desentralisasi Fiskal, Tax Effort, dan Pertumbuhan Ekonomi Daerah: Studi Empirik Kabupaten/Kota Se-Indonesia 2001-2008, Tesis. Bogor (ID): Institut Pertanian Bogor.

Arniwita, A., Santoso, A., Kurniasih, E. T., \& Soleh, A. 2019. Dampak Penyerapan Anggaran Terhadap Kinerja Instansi Pemerintah (Studi Kasus di Provinsi Jambi). Ekonomis: Journal of Economics and Business, 3(2), 166-170.

Bastian, I. 2006. Sistem Perencanaan dan Penganggaran Pemerintah Daerah di Indonesia. Jakarta: Salemba Empat.

Baltagi, B. H. 2005. Econometric Analysis of Panel Data. Chichester: Jhon Wiley \& sons Ltd.

Ekawarna, S. U. 2017. Analisis Flypaper Effect pada Belanja Daerah (Studi Komparasi Daerah Induk dan Pemekaran kabupaten/kota di Provinsi Jambi). Jurnal Perspektif Pembiayaan dan Pembangunan Daerah, 4(3), 167-184.

Fitra, H., Mukhlis, F., \& Dani, S. R. 2020. Analisis Kinerja Keuangan Pemerintah Daerah Kabupaten Induk dan Kabupaten Pemekaran: Studi Kasus Kabupaten Sijunjung dan Kabupaten Dharmasraya. Jurnal Inovasi Pendidikan Ekonomi (JIPE), 10(1), 25-39.

Gujarati, D. 2003. Ekonometrika Dasar. Jakarta: Erlangga.

Jaenuri. 2016. Analisis Perbandingan Kinerja Keuangan Pemerintah Bojonegoro dan Jombang Tahun $2010-2014$. Jurnal Ekonomi Pembangunan, 14(1).

Nasional, B. P. P. 2009. Studi Evaluasi Dampak Pemekaran Daerah 2001-2007.

PP.No.78 tahun 2007. 2007. Tata Cara Pembentukan, Penghapusan, dan Penggabungan Daerah. Indonesia: Republik Indonesia

Riani, I. A. P., \& Kaluge, D. 2011. Analisis Perbandingan Kinerja Keuangan Daerah Pemekaran di Provinsi Papua. Jurnal Aplikasi Manajemen, 9(3), 809-817.

Swaniewicz, P. 2002. Consolidation or Fragmentation? The size of local Goverments in Central and Eastern Europe. Local Goverment and Public Service Reform. Budapest: Open Society Institute Budapest.

Sjafrizal. 2008. Ekonomi Regional Teori dan Aplikasi. Padang : Baduose Media.

Soleh, A., Putra, I. E., \& Rahayu, Y. 2017. Analisis Kinerja Aparatur Dan Pelayanan Publik Sebagai Dasar Menuju Reformasi Birokrasi Yang Ideal. Jurnal Development, 5(2), 110-124.

Soleh, A. 2013. Analisis Kinerja Keuangan Provinsi Jambi. Jurnal Development, 1(1), 61-70.

Taufik, T. (2017). Analisis Perbandingan Kinerja Keuangan Pemerintah Kabupaten Kota Se-Sumatera. Gema Ekonomi, 7, 993-1012.

Trikurniasih, E., Handayani, R., Santoso, A., \& Soleh, A. 2019. Analisis Dampak Pemekaran Daerah Terhadap Kinerja Keuangan dan Pelayanan Publik. Ekonomis: Journal of Economics and Business, 3(2), $159-165$.

Undang-undang No. 32 Tahun 2004. Pemerintah Daerah. Jakarta: Republik Indonesia

Undang- undang No 34 tahun 2000. Pemerintahan Daerah. Jakarta: Pemerintah Republik Indonesia. 